TẠP CHÍ KHOA HỌC ĐẠI HỌC TÂN TRÀO

ISSN: $2354-1431$

http://tckh.daihoctantrao.edu.vn/

\title{
Tín hiệu văn hóa trong ngôn ngũ̃ ca dao và thơ hiện đại
}

\author{
Lê Đức Luận ${ }^{a^{*}}$ \\ ${ }^{a}$ Đại học Su phạm - Đại học Đà Nã̃ng \\ Email: leducluan3@gmail.com
}

\section{Thông tin bài viết}

Ngày nhận bài:

29/01/2018

Ngày duyệt đăng:

$10 / 3 / 2018$

\section{Tù khoá:}

Tín hiệ; văn hóa; ngôn ngũ; nông nghiẹp; nghè nghiẹp;phong tuc tập quán; lò̀i nói; bản sắc; vùng miền;không gian văn hóa dân tộc.

\section{Dẫn nhập}

Tín hiệu ngôn ngữ là các đơn vị thuộc hệ thống ngôn ngữ nhưng trong thơ thì biểu hiện chủ yếu ở cấp độ từ và những cấu trúc tương đương từ như ngữ cố định. Văn học phản ánh và chứa đựng văn hóa phần lớn dưới dạng các biểu tượng, các hình tượng biểu thị trong các tín hiệu ngôn ngữ. Tín hiệu văn hóa là dấu hiệu ngôn ngữ cho ta nhận biết ý nghĩa văn hóa, biểu trưng văn hóa. Tín hiệu ngôn ngữ có ý nghĩa biểu trưng chính là tín hiệu thẩm mĩ [14]. Ngôn ngữ thơ có khả năng biểu thị hiệu quả những hình ảnh mang tín hiệu văn hóa. Những nhà thơ tài hoa thường có khả năng đem vào thơ những tín hiệu ngôn ngữ biểu thị văn hóa. Những tín hiệu văn hóa trong thơ thường được chỉ xuất từ văn hóa dân gian, từ cội nguồn văn hóa dân tộc, từ nếp sống sinh hoạt của dân tộc, đặc điểm địa lí và lịch sử xã hội Việt Nam.

Trong bài viết này tôi đề cập đến tín hiệu ngôn ngữ, trong đó có tín hiệu thẫm mĩ. Tín hiệu ngôn ngữ đơn thuần chỉ là những tín hiệu biểu vật và biểu niệm còn tín hiệu thẩm mĩ là những tín hiệu mang ý nghĩa hàm ngôn, có giá trị biểu trưng cao hơn. Tín hiệu văn hóa là tín hiệu ngôn ngữ biểu thị những sự vật trong phạm trù văn hóa và biểu trưng ý nghĩa văn hóa. Bài viết dẫn liệu một số bài ca dao và một số bài thơ hiện đại như là minh chứng tiêu biểu cho những vấn đề ngôn ngữ văn hóa.

\section{Biểu hiện văn hóa trong ngôn ngũ̃ thơ}

\subsection{Tín hiệu biểu trung văn hóa nghề nghiệp và}

\section{khung cảnh làng quê}

Đặc trưng nghề nông và văn hóa làng quê Việt trong thơ thể hiện trong các tín hiệu ngôn ngữ biểu trưng: đồng lúa, cánh cò, bến nước, con đò, dòng sông, nhà mái tranh. Từ bao đời nay, thôn quê Việt gắn bó với cánh đồng xanh rờn trải dài tít tắp và cánh cò bay rập rờn trên các ruộng lúa, bờ kênh. Trong ca dao, hình ảnh quê nhà và các món ăn quen thuộc trong cấu trúc ngữ cố định "canh rau muống, cà dầm tương" (có ý kiến đây là hình ảnh trong bài thơ của Á Nam Trần Tuấn Khải được dân gian hóa). Tín hiệu "cái cò" biểu trưng hình ảnh làng quê và người nông dân trong ngôn ngữ ca dao: "Cái cò bay lả bay la/Bay tù̀ cưa phủ bay ra cánh đồng". Trong thơ Nguyễn Đình Thi, hình ảnh làng quê Việt Nam trong cấu trúc: biển lúa, cánh cò, rập rờn: "Mênh mông biển lúa đâu trời đẹp hơn/Cánh cò bay lả rập rờn" (Bài ca Hắc Hải) mang vẻ đẹp hồn hậu. Một miền quê yên ả trong thơ Đoàn Văn Cừ, biểu trưng làng quê Việt đẹp trong các cấu trúc tín hiệu: cánh cò, giăng 
hàng, phấp phới: "Đàn cò trắng giăng hàng bay phấp phơì" (Đám cuoói mùa xuân). Vẻ đẹp bình dị của thôn quê Việt với "mái nhà tranh" trong thơ Hàn Mặc Tử: "Trong làn nắng ưng: khói mo tan/Đôi mái nhà tranh lấm tấm vàng" (Mùa xuân chín). Ngôi vườn xưa Huế với "hàng cau" cổ kính: "Nhìn nắng hàng cau nắng mói lên" (Đây thôn Vĩ Da - Hàn Mặc Tử). Hình ảnh làng quê Việt thanh bình trong thơ Anh Thơ với những tín hiệu đặc trưng: bến, đò, sông, quán tranh, còm xoan: "Mưa đổ bưi êm êm trên bến vắng/Đò biếng luời nằm mặc nước sông trôi/Quán tranh đứng im lim trong vắng lặng/Bên chòm xoan hoa tím rụng tơi bời" (Chiều xuân). Một mùa xuân êm đềm trong không gian làng quê tĩnh lặng.

Việt Nam, đất nước có bốn mùa hoa tươi quả ngọt, những tín hiệu ngôn ngữ biểu thị các loại hoa quả bốn mùa. Tín hiệu "màu xanh" biểu tượng đặc trưng của cảnh sắc thôn quê với hoa thơm, trái ngọt:"Việt Nam đất nắng chan hoà/ Hoa thom quả ngọt bốn mùa tròi xanh" (Nguyễn Đình Thi-Bài ca Hắc Hải). Màu xanh lại được đặc tả trong cảnh vườn quê xứ Huế cổ kính: "Vườn ai muoót quá xanh nhu ngọc" (Hàn Mặc Tử -Đây thôn $V i ̃ ~ D a$ ). Một không gian vườn quê với cảnh quan vườn cây, ao cá, hoa sen: "Hồng trong nắng sơm, biếc trong vươn chiều/Quả lành trĩu nặng tùng cây/Sen đầy ao cá, cá đầy ao sen" (Nguyễn Bính-Anh về quê cũ). Cảnh quê trù phú với hoa trái xanh tươi trên vùng đất bãi bồi bên sông: "Xanh xanh bãi mía bờ dâu/Ngô khoai biêng biếc" (Hoàng Cầm - Bên kia sông Đuống). Trong ca dao, màu xanh của hoa sen làm nổi bật màu trắng của bông và màu vàng của nhị, thể hiện cách tả độc đáo từ ngoài vào trong, từ trong ra ngoài để nhấn mạnh hương thơm của hoa sen mặc dù bài ca không biểu thị mùi hương: "Trong đầm gì đẹp bằng sen/ Lá xanh bông trắng lại chen nhị vàng/ Nhị vàng bông trắng lá xanh/ Gần bùn mà chẳng hôi tanh mùi bùn". Hoa sen biểu thị cốt cách, khí tiết, vẻ đẹp tâm hồn của người Việt. Bài ca không tả mùi hương nhưng lại tả mùi hương đạt nhất bởi mùi hương đặc trưng của hoa sen đã át mùi bùn. Sống trong bùn, không bị lây nhiễm sự hôi tanh của bùn là nhờ bản lĩnh sống của hoa sen. Như vậy, có nhiều tín hiệu về các loại màu sắc nhưng tín hiệu màu xanh là tín hiệu đặc trưng của làng quê Việt với các dạng biểu thị khác nhau: trời xanh, vườn xanh biếc, lá xanh, cây xanh. Đấy cũng là tín hiệu đặc trưng cây trái nông nghiệp.

Bên cạnh nghề chủ đạo là nghề nông thì còn có các nghề thủ công truyền thống. Đó là các tín hiệu biểu thị nghề gắn với các nguyên liệu và quá trình làm ra chiếc nón độc đáo, chiếc nón bài thơ, các mành tre trúc mĩ thuật: "Tay người như có phép tiên/ Trên tre lá cũng dệt nghìn bài thơ" (Nguyễn Đình Thi-Bài tho Hắc Hải). Những nghề thủ công gắn với trồng dâu nuôi tằm, dệt vải, nhuộm vải của những vùng quê quanh châu thổ sông Hồng: "Những nàng dệt sợi/Đi bán lụa màu/Những người thợ nhuộm/Đồng Tỉnh, Huê Cầu" (Hoàng Cầm-Bên kia sông Đuống”.

Ca dao Hà Nội nói đến các nghề buôn, dệt, làm bánh: "Con gái kẻ Cót thì đi buôn xề/Con trai làng Nghè dệt củi kéo hoa/An Phú nấu kẹo mạch nha/Làng Vòng làm cốm để mà tiến vua..." [10].

\subsection{Tín hiệu biểu trung ẩm thưc, phong tục, lễ hội làng}

Hương vị quê da diết với những món ăn thức uống đồng nội. Hương vị lúa nếp: "Quê huoong ta lúa nếp thơm nồng” (Hoàng Cầm - Bên kia sông Đuống), hương cốm vào độ thu về: "Gió thổi mùa thu huơng cốm mó́i" (Nguyễn Đình Thi - Đất nước). Thói quen ăn uống biểu thị các cấu trúc ngôn ngữ: "ăn cháo, ăn rau, ăn ớt, uống rượu, ăn trầu" (Nguyễn Khoa Điềm Mặt đường khát vọng). Những món ăn quê bình dị: ngô, khoai, rau muống, quả cà nhưng để lại nỗi nhớ trong tâm hồn những người con đất Việt: "Nhó đồng ruộng, nhớ khoai ngô/ Bát cơm rau muống quả cà giòn tan" (Nguyễn Đình Thi-Bài tho Hắc Hải). Văn hóa nông nghiệp với thói quen ăn uống thiên về thực vật là đặc trưng cơ bản của ẩm thực Việt biểu hiện cụ thể từ ca dao đến thơ hiện đại.

Nét đẹp trong văn hóa ẩm thực Việt bắt nguồn từ chính dấu ấn của nền nông nghiệp lúa nước. Từ bữa ăn hàng ngày đến tiệc tùng hội hè, đình đám trong thực đơn của người Việt đều có cơm. Từ "cơm" chỉ món cơm nói chung: "Uớc khi nào hợp một nhàl Chồng cày vợ cấy me già đura cơm”. Sau món cơm là canh với các thực phẩm sông nước: "Không đi thì sọ quan đòi/ Ra đi thì nhớcá mòi nấu canh". Các món kho, luộc mặn mà: "Chiều chiều ra đứng cưa sau/Thấy em kho mắm luộc rau anh thèm". Người Việt ít khi chỉ ăn có một món trong bữa cơm mà ăn nhiều món, trong một món cũng có nhiều chất tổng hợp. Ngay trong món canh rau thì không chỉ một loại rau mà kết hợp nhiều loại rau, gọi là rau tập tàng: "Ta về ta sắm cần câu/Câu lấy cá bống nấu rau tập tàng"..[13]

Cảnh sinh hoạt lễ hội, thú vui tiêu khiển, các trò chơi dân gian với những sinh hoạt hội hè vào độ xuân về được thể hiện rất sinh động trong từ ngữ thơ Hoàng Cầm, Nguyễn Bính. Đó là những từ ngữ biểu thị lễ hội 
đình, lễ hội chùa: "Mưa xuân rắc buii quanh làng/Bà già sắm sưa hành trang đi chùa/Ông già vào núi đề tho/ Trai to đình đám, gái to hội hè" (Nguyễn Bính-Tỳ bà truyện). Làng quê tràn ngập không khí náo nức và linh thiêng của lễ hội. Các tín hiệu biểu thị không gian tín ngưỡng: núi Thiên Thai, chùa Tháp Bút: "Nhũng hội hè đình đám/Trên núi Thiên Thai/ Trong chùa Bút Tháp /Giũa huyện Lang Tài”" (Hoàng Cầm-Bên kia sông Đuống). Đó là những ngày hội văn nghệ dân gian với những tín hiệu biểu thị địa danh văn hóa tiêu biểu: làng Đặng, thôn Đoài "Hội chèo làng Đặng đi qua ngõ/Mẹ bảo thôn Đoài hát tối nay"(Nguyễn Bính-Mua xuân). Tín hiệu biểu thị những sinh hoạt thuần hậu, bình dị mà sảng khoái, thanh tao của người dân thôn quê, những trò vui hồn nhiên của trẻ thơ như thả diều, thả thuyền: "Đê cao có đất thả diều/Trời cao lắm lắm có nhiều chim bay/Hiu hiu gió quạt trăng đèn/Với dăm trẻ nhỏ thả thuyền ta choì"(Nguyễn Bính-Anh về quê cũ). Những thú vui tao nhã và ẩm thực Việt qua từ ngữ thơ: " $\breve{A n}$ gỏi cá, đánh cò người Thần tiên riêng một góc trời thôn Vân" (Nguyễn Bính-Anh về quê $c \tilde{u}$ ). Vâng, thật là một cảnh vui thú thần tiên ở chốn trần gian.

Tín hiệu ngôn ngữ biểu thị phong tục làng quê trong phiên chợ Tết và đám cưới. Nhà thơ Đoàn Văn Cừ đã khắc họa được cảnh sắc làng quê và không khí tưng bừng náo nức trong phiên chợ Tết. Tín hiệu biểu trưng không gian làng quê sáng tinh sương mùa xuân: ráng bình minh đỏ dần, sương sớm trên nóc nhà, con đường và đồi xanh "Dái mây trắng đỏ dần trên đỉnh núi/Surong hồng lam ôm ấp nóc nhà gianh/Trên con đường viền trắng mép đồi xanh (Đoàn Văn Cừ-Chơ Tết). Không khí vui vẻ tưng bừng: "Người các ấp turng bùng ra chọ Tết/Ho vui vẻ kéo hàng trên cỏ biếc." (Đoàn Văn Cừ-Chơ Tết) Phong tục thưởng thức thơ xuân và câu đối đỏ cầu chúc năm mới đã trở thành nếp sống: "Một thầy khóa gò lung trên cánh phản/Tay mài nghiên hí hoáy viết tho xuân/Cu đồ nho dùng lại vuốt râu cằm/Miệng nhẩm đọc vài hàng câu đối đỏ" (Đoàn Văn Cừ-Chơ Tết). Trong không gian nguyên sơ ấy, những phong tục cổ truyền được giữ nguyên trạng với thú chơi tranh, câu đối, thơ xuân: "Anh hàng tranh kĩu kịt quảy đôi bồ/Tìm đến chố đông người ngồi giở bán" (Đoàn Văn Cừ-Chơ Tết). Tranh Tết thường được người Việt ưa chuộng là tranh Đông Hồ và Hàng Trống: "Tranh Đông Hồ gà lợn nét turơi trong" và Hoàng Cầm đã rất tinh tế khi phát hiện ra đó là "Màu dân tộc sáng bùng trên giấy điệp" (Hoàng Cầm-Bên kia sông Đuống). Màu dân tộc biểu thị qua tín hiệu: tranh gà lợn, màu tươi trong.

Các nhà thơ đã đem vào thơ nếp sống sinh hoạt, phong tục mặc mang đậm văn hóa Việt. Những dấu chỉ văn hóa thể hiện trong các từ ngữ thơ biểu thị cách ăn mặc, nếp sống của người dân quê. Những năm 30 đến 50 của thể kỉ hai mươi, cách ăn mặc sinh hoạt của người dân thôn quê vẫn còn thể hiện nét "chân quê", với mặc yếm thắm, răng đen, ăn trầu: "Nhũng cô hàng xén răng đen/Cười nhu mùa thu tỏa nắng" (Hoàng Cầm-Bên kia sông Đuống); “Trên đuoòng cát mịn một đôi cô/Yếm đỏ khăn thâm trẩy hội chùa" (Nguyễn Bính-Xuân về). Màu sắc chủ đạo của người Việt biểu thị là màu đen, màu nâu (thâm, chàm): “Áo chàm đưa buổi phân li” (Tố Hữu-Việt Bắc), "Gái trai cũng một áo nâu nhuộm bùn" (Nguyễn Đình Thi- Bài tho Hắc Hải), "Nhũng em xột xoạt quần nâu" (Hoàng CầmBên kia sông Đuống). Màu đen, nâu, vàng là màu tối, phù hợp với màu đất, là màu mát phù hợp với lối sống nông nghiệp và khí hậu nóng nực. Màu đen là màu nổi trội: răng đen, quần đen, tóc đen. Đoàn Văn Cừ đã ghi lại khung cảnh một lễ đưa dâu của đám cưới quê những năm đầu thế kỉ hai mươi với cách trang phục đi lại lộng lẫy, trang nghiêm, nền nã. Các cụ ông thì “Mặc áo đỏ, cầm huoong đi truớc đám /Dăm sáu cu áo mền bông đỏ sẫm/Quần nâu hồng, chống gậy buớc theo sau". Nếu các ông che "ô đen" thì các cụ bà: "Đầu nón Nghệ, tay cầm khăn mặt đò" và "Túi đựng trầu chăm chăm giũ trong tay". Trong khi các chàng trai: "Quần lụa chùng, nón dứa áo sa huê" thì các cô gái nào là: "váy lĩnh, dép quai cong", nào là: "Áo đồng lầm, yếm đỏ, thắt lung xanh". Các cháu bé thì: "Đầu cạo nhã̃n, áo vàng, quần nâu sẫm”. Đặc biệt nổi bật là cô dâu thật "choáng lộn" với "Vành khuyên vàng, áo mó, nón quai thao" (Đoàn Văn Cừ-Đám cuới mùa xuân). Những từ ngữ biểu thị nhiều loại trang phục dân tộc đẹp mà nền nã. Áo thì đủ loại, từ áo trong đến áo ngoài: yếm đỏ, áo mớ,áo mền bông, áo đồng lầm, áo sa huê,áo vàng. Quần cũng đủ kiểu: quần nâu hồng, quần lụa chùng, váy lĩnh, quần nâu sẫm. Ngoài ra còn có các thứ đội, đeo: nón Nghệ, nói quai thao, thắt lung xanh, vành khuyên vàng. Bên cạnh các màu tối thì có màu sáng chói như màu đỏ, màu hồng được cho là màu may mắn, thịnh vượng.

2.3. Tín hiệu biểu trung văn hóa dân gian và sắc thái văn hóa vùng đất

Các chỉ dấu văn hóa dân gian đậm đặc nhất thể hiện trong bài thơ "Đất nước" của Nguyễn Khoa 
Điềm. Tác giả đã đem vào thơ những biểu tượng lấy từ kho tàng văn hóa dân gian. Không gian lãnh thổ Tổ quốc, không gian thiêng liêng từ thời tổ tiên cư trú. Các tín hiệu biểu trưng các nhân vật huyền thoại trong truyền thuyết Việt về nguồn gốc giống nòi, đó là Lạc Long Quân và Âu Cơ: "Đất là nơ Chim về/Nước là noi Rồng ở/Lac Long Quân và Âu Co". Thay vì trời và đất thì đất và nước là biểu tượng của hai vùng lãnh thổ tiêu biểu của cư dân Lạc Việt. Đó cũng là không gian tự nhiên từ rừng vàng đến biển bạc: "Đất là nơi con chim phương hoàng bay về hòn núi bạc/Nước là nơi con cá ngu ông móng nước biển khoit". Đó là không gian của anh và em, cặp âm dương trai gái hòa hợp được hiện diện trong không gian sinh hoạt đời thường: "Đất là noi anh đến truờng/Nuớc là noi em tắm/Đất nuớc là noi ta hò hẹn/Đất nuớc là noi em đánh rơi chiếc khăn trong nỗi nhớ thầm".

Đất nước tạo dựng bởi những người bình dân qua suốt chiều dài lịch sử, tạo nên dáng vẻ hình hài bằng tình yêu chung thủy: "núi Vọng Phu, hòn Trống máii; sự cần cù hiếu học "núi Bút non Nghiên...", để lại dấu ấn của mình trong các địa danh: "Nhũng nguời dân nào đã góp tên ông Đốc, ông Trang, bà Đen, bà Điểm". Đặc điểm địa hình, các danh thắng thiên nhiên cũng được Nguyễn Khoa Điềm được chỉ dấu từ các truyền thuyết dân gian: "Gót ngựa của Thánh Gióng đi qua còn trăm ao đầm để lại/Chín muoơi chín con voi góp mình dưng đất tổ Hùng Vương/Nhũng con rồng nằm im góp dòng sông xanh thẳm/Con cóc con gà quê huơng cùng góp cho Hạ Long thành thắng cảnh". Tác giả nói về đặc điểm địa danh từ nguồn gốc tên gọi, lí do tên gọi mà còn nói đến ý thức cội nguồn của việc đặt tên: "Ho gánh theo tên xã, tên làng trong mỗi chuyến di dân". Đấy chính là ý thức lưu giữ địa danh nơi chôn rau cắt rốn đặt cho nơi ở mới trong quá trình đi mở cõi của người Việt. Có thể nói rằng, đặc điểm lịch sử văn hóa dân tộc Việt đã được Nguyễn Khoa Điềm thể hiện một cách hình tượng trong các từ ngữ chỉ dấu văn hóa dân gian.

Tín hiệu ngôn ngữ biểu thị các làn điệu dân ca sông nước: hò sông Mã, hò khoan Lệ Thủy, hò mái nhì, hò mái đẩy, hò kéo thuyền..."Ôi nhũng dòng sông bắt nuớc tì̀ đâu/Mà khi về đất nuơóc mình thì bắt lên câu hát/Ngườ đến hát khi chèo đò, kéo thuyền vuoọt thác". Đấy chính là hình tượng người Việt Nam cần cù lao động, lạc quan, yêu đời ham sống.

Trong thơ, sự chỉ dấu văn hóa giao tiếp thể hiện ở lời ăn tiếng nói dân gian, vừa có tính phổ quát vừa có sắc thái vùng miền. Sắc thái văn hóa vùng biểu hiện ở các chỉ dấu về đặc điểm tự nhiên, món ăn thức uống, sinh hoạt. Nhà thơ Tố Hữu rất chú trọng sử dụng lời ăn tiếng nói dân gian. Phương ngữ miền Trung, đặc biệt là chất giọng Huế đã tạo cho thơ Tố Hữu một âm điệu riêng, nó toát lên phần nào khí chất của con người nơi đây. Từ "cơ chi" trong "Bài ca quê huoong" gần nghĩa với "giá mà" nhưng trìu mến, da diết: "Ôi, co chi anh được về với Huếl Không đợi trua nay phuợng nơ với cò̀ Co chi anh được về bên nội/ Hôn nỗi đau tan nát Phù Lai”. Chất giọng Quảng Bình với các từ phương ngữ đặc trưng Bắc miền Trung trong các từ "chừ, chi, rứa, răng, nờ...”: "Bây chù sông nước về ta/ Gan chi, gan rúa, me nò?? Có răng ông cũng ung cho mẹ chèo?" (Mẹ Suốt) [9]

Tố Hữu chú trọng đến ngôn ngữ biểu thị đặc điểm khí hậu, núi rừng và sản vật của vùng đất. Đặc điểm thổ nhưỡng, khí hậu, cư trú của vùng núi Việt Bắc thể hiện trong các từ ngữ: mưa nguồn, suối lũ, mây mù, trăng lên đầu núi, nắng chiều lưng nương, mơ nở trắng rừng, bản khói cùng sương "Mưa nguồn suối lũ nhũng mây cùng mù/Trăng lên đầu núi nắng chiều lung nuoong/...bản khói cùng suoong/Ngày xuân mo nở trắng rùng". Sản vật miền núi đặc trưng là tre, nứa, phách, trám bùi, măng mai, ngô: "Trám bùi để rụng, măng mai để già/ Nhớ tùng rùng nứa bò tre/Thuơng nhau, chia củ sắn lùi/Địu con lên rẫy bẻ tùng bắp ngô....". Nổi bật là cảnh sinh hoạt đầy tự tin, khỏe khoắn của người dân: "Đèo cao nắng ánh dao cài thắt lung/... cô em gái hái măng một minh/... người me nắng cháy lung/Địu con lên rẫy bẻ tùng bắp ngô". Nguyễn Đình Thi tả khí trời và phố Hà Nội vào thu chỉ một câu thơ với từ ngữ chỉ dấu đặc trưng: hơi may, phố dài "Nhũng phố dài xao xác hoi may" (Đất nuớc).

\section{Kết luận}

Những yếu tố văn hóa Việt trong thơ phần lớn là những tín hiệu thẩm mĩ biểu thị đặc trưng văn hóa dân tộc. Văn hóa dân tộc trong thơ thường đề cập đến văn hóa nông nghiệp, làng quê, phong tục tập quán thuần hậu. Đặc trưng văn hóa dân gian, văn hóa vùng miền qua các từ ngữ biểu thị sản vật, món ăn thức uống. Chất giọng, cách nói năng thể hiện qua phương ngữ thể hiện trong các từ ngữ giao tiếp.

Ca dao là một loại hình thơ dân gian thể hiện khá rõ đặc trưng văn hóa Việt, đặc biệt là văn hóa nông nghiệp. Những nhà thơ mà các tác phẩm biểu thị những tín hiệu văn hóa Việt thường thường có lấy các từ ngữ thuần Việt, cách nói năng của quần chúng nhân dân. Những tác phẩm thơ thể hiện văn hóa dân tộc 
thường có sức cuốn hút lớn đối với người đọc qua nhiều thế hệ.

\section{TÀI LIỆ THAM KHẢO}

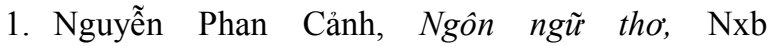
ĐH\&GDCN, H, 1987;

2. Nguyễn Văn Chiến, Tiến tới xác lập vốn tù̀ vưng văn hóa Việt, Nxb KHXH, H, 2004;

3. Hữu Đạt, Văn hoá và ngôn ngũ giao tiếp của nguời Việt, Nxb VHTT, H, 2000;

4. Nguyễn Văn Độ, Tìm hiểu mối quan hệ ngôn ngũvăn hoá, Nxb ĐHQG Hà Nội, 2004;

5. Hà Minh Đức, Tho và mấy vấn đề trong tho Việt Nam hiện đại, Nxb KHXH, H 1974;

6. Đinh Hồng Hải, Nghiên cứu biểu tuợng. Một số huớng tiếp cận lý thuyết, Nxb Thế giới, H, 2014;

7. Nguyễn Lai, Ngôn ngũ với sáng tạo và tiếp nhận văn họ, Nxb GD, H, 1996;

8. IU.M.Lotman, Ki hiệu học văn hóa. Người dịch: Lã Nguyên, Đỗ Hải Phong, Trần Đình Sử, Nxb Đại học Quốc gia Hà Nội, 2016;
9. Lê Đức Luận, Vai trò của phương ngũ địa lí và phuơng ngũ xã hội với sụ phát triển tiếng Việt, Kỉ yếu Hội thảo ngôn ngữ, Viện Ngôn ngữ học, Hội Ngôn ngữ thành phố Hồ Chí Minh, 2002;

10. Lê Đức Luận, Âm vang địa danh Hà Nội trong ca dao dân ca, Ngôn ngữ và Đời sống, số $1+2$ (123+124), H, 2006;

11. Lê Đức Luận, Cấu trúc ca dao trũ tình người Việt, Nxb Đại học Huế, 2009;

12. Lê Đức Luận, Điểm nhìn nghiên cưu văn họ, Tái bản, Nxb Văn học, H, 2011;

13. Lê Đức Luận, Đặc điểm ngôn ngũ và văn hóa của tù ngũ biểu thị pham trù "ăn” trong ca dao người Việt, Tạp chí Khoa học và giáo dục, Đại học Sư phạm, ĐHĐN, Số 23 (02), 2017;

14. Mai Thị Kiều Phượng, Tín hiệu thẩm mĩ trong ngôn ngũ hoc, Nxb Khoa học Xã hội, H, 2008;

15. Trần Ngọc Thêm, Cơ sở văn hoá Việt Nam, Nxb GD, H, 1998.

\section{Cultural language signal in folk poetry and modern poetry}

Le Duc Luan

\section{Article info}

Recieved:

29/01/2018

Accepted:

10/3/2018

\section{Keywords:}

Signal; culture; language; Agriculture; employment; customs; words; identities; regional; national cultural space.

\begin{abstract}
Cultural signal is a sign language for us to realize its cultural significance and, symbolic culture. These cultural signals in poetry are usually go from folklore, from the national cultural roots, from normal life of the nation, geographical features and social history of Vietnam. Signal cultural expression in the language of poetry include: agricultural culture and village, professional culture, customs, voice replies, regional identity, national cultural space. The Vietnamese cultural element in poetry is the aesthetic signal characterization ethnic culture.
\end{abstract}

